\title{
Amelioration of Experimental Amnesia (Passive Avoidance Failure) in Rodents by the Selective M1 Agonist AF102B
}

\author{
Noboru NAKAHARA, Yoshinori IGA, Fumio MIZOBE \\ and Gosei KAWANISHI \\ Research Institute of Life Science. Snow Brand Milk Products Co.. Ltd., \\ 519 Ishibashi-machi, Shimotsuga-gun, Tochigi 329-05. Japan
}

Accepted September 30, 1988

\begin{abstract}
Effect of AF102B (cis-2-methylspiro-(1,3-oxathiolane-5,3')-quinuclidine) on experimental amnesia was examined using a passive avoidance task in rodents. The amnesia was produced by anti-cholinergic agents, AF64A (intracerebroventricularly) and scopolamine (subcutaneously). AF102B ameliorated the memory deficits in AF64A-treated rats at $0.1-1 \mathrm{mg} / \mathrm{kg}$, i.p. and at $1-5 \mathrm{mg} / \mathrm{kg}$ p.o. and in scopolamine-treated mice at $1-10 \mathrm{mg} / \mathrm{kg}$. i.p. These results suggest that AF102B may compensate for central cholinergic defects and could be developed as a possible therapeutic drug for senile dementia of the Alzheimer type.
\end{abstract}

The most notable symptoms in senile dementia of the Alzheimer type (SDAT) are generally characterized by a memory loss of recent events and cognitive deficits. In SDAT, abnormalities of several neurotransmitter systems in the brain have been reported, including cholinergic, noradrenergic, serotoninergic and somatostatinergic systems ( 1 , 2 ). Among them, the abnormality in cholinergic system is generally greater and more consistent and is found to correlate well with the cognitive deficits (1-3). Moreover, ample evidence has suggested that cholinergic function is involved in memory and cognitive functions in humans as well as animals (4). These observations rationalize clinical trials with compounds that enhance cholinergic transmission such as acetylcholinesterase inhibitors (physostigmine, tetrahydroaminoacridine) and muscarinic agonists (arecoline, oxotremorine, RS 86). A substantial number of studies have reported modest but significant improvements, but not without suffering from serious limitations such as short duration of action and a narrow therapeutic window $(1,5)$. These results encouraged us to develop a cholinomimetic compound as a therapeutic drug for SDAT. Since no conclusive animal models are yet available, the efficacy of compounds should be evaluated in various ani- mal models before final clinical trials. Scopolamine-induced experimental amnesia mice (SCP-mice) are widely used as an animal model for memory disorders including SDAT (4). Intracerebroventricular (i.c.v.) injection of a putative cholinotoxin AF64A brings about a cholinergic hypofunction in the hippocampus together with memory deficits, indicating that AF64A-treated rats (AF64Arats) are workable animal model for SDAT (6). In the present paper, we have examined effects of AF102B, a novel muscarinic agonist of the $M_{1}$-type receptor, on passive avoidance failures in AF64A-rats and SCPmice. A preliminary report of part of this work has been published elsewhere (7).

AF102B (cis-2-methylspiro-(1.3-oxathiolane-5.3')-quinuclidine hydrochloride hemihydrate) and acetyl-AF64 were synthesized and provided by Dr. A. Fisher (Israel Inst. Biol. Res., Ness-Ziona, Israei). (-)Scopolamine hydrochloride, oxotremorine sesquifumarate and arecoline hydrobromide were purchased from Sigma (St. Louis, U.S.A.). AF64A (ethylcholine aziridinium ion) was freshly prepared by alkaline hydrolysis of acetyl-AF64 (8). The surgery and passive avoidance test were carried out as described elsewhere (8). Briefly, male Sprague-Dawley rats (200-250 g, Charles 
River Japan, Atsugi) were bilaterally injected with AF64A ( $3 \mathrm{nmol} / 2 \mu l$ per side) or saline solution (vehicle) into the lateral ventricles. Rats were subjected to a one-trial stepthrough passive avoidance task 19-21 days after surgery. AF102B (0.1 or $1 \mathrm{mg} / \mathrm{kg})$, oxotremorine $(0.03$ or $0.1 \mathrm{mg} / \mathrm{kg})$, arecoline (1 or $5 \mathrm{mg} / \mathrm{kg}$ ) or saline solution (vehicle) were intraperitoneally administered immediately after the acquisition trial. In some experiments, AF102B $(0.2,1$ or $5 \mathrm{mg} / \mathrm{kg})$ or distilled water (vehicle) were perorally administered $30 \mathrm{~min}$ before the acquisition trial. The retention trial was carried out $24 \mathrm{hr}$ after the acquisition trial. Latency time was recorded up to a maximum of $600 \mathrm{sec}$.

Male ddy mice (25-30 g. Shizuoka Laboratory Animal Center, Hamamatsu) were subjected to a one-trial passive avoidance task. A step-through type apparatus for mice was used. Scopolamine $(1 \mathrm{mg} / \mathrm{kg})$ was subcutaneously injected $30 \mathrm{~min}$ before the acquisition trial. For control mice, saline solution was injected. After a 30-sec habituation in the light chamber, each mouse was allowed to enter the dark chamber by removing a guillotine door. Upon entry into the dark chamber, the mouse received foot shock ( $250 \mathrm{~V}, 50 \mathrm{HzAC}$ ) for $1 \mathrm{sec}$. Initial latency time to enter the dark chamber was recorded. The mice that had an initial latency time of more than $60 \mathrm{sec}$ were excluded from further experiments. AF102B (1.5 or $10 \mathrm{mg} / \mathrm{kg}$ ) or saline solution (vehicle) were intraperitoneally administered immediately after the acquisition trial. Retention of the passive avoidance task was evaluated $24 \mathrm{hr}$ after the acquisition trial. Retention latency time was recorded up to a maximum of $600 \mathrm{sec}$.

In the retention trial, saline-treated control rats exhibited a long response latency of 600 sec (Fig. 1a). In contrast, the latency of AF64A-rats receiving vehicle was significantly shorter than that of control rats, in agreement with our previous result (8). AF102B (0.1 or $1 \mathrm{mg} / \mathrm{kg}$, i.p.) administration to AF64A-rats produced a significant improvement of a passive avoidance response (Fig. 1a). Oxotremorine significantly enhanced the retention test performance of

(a)

(b)

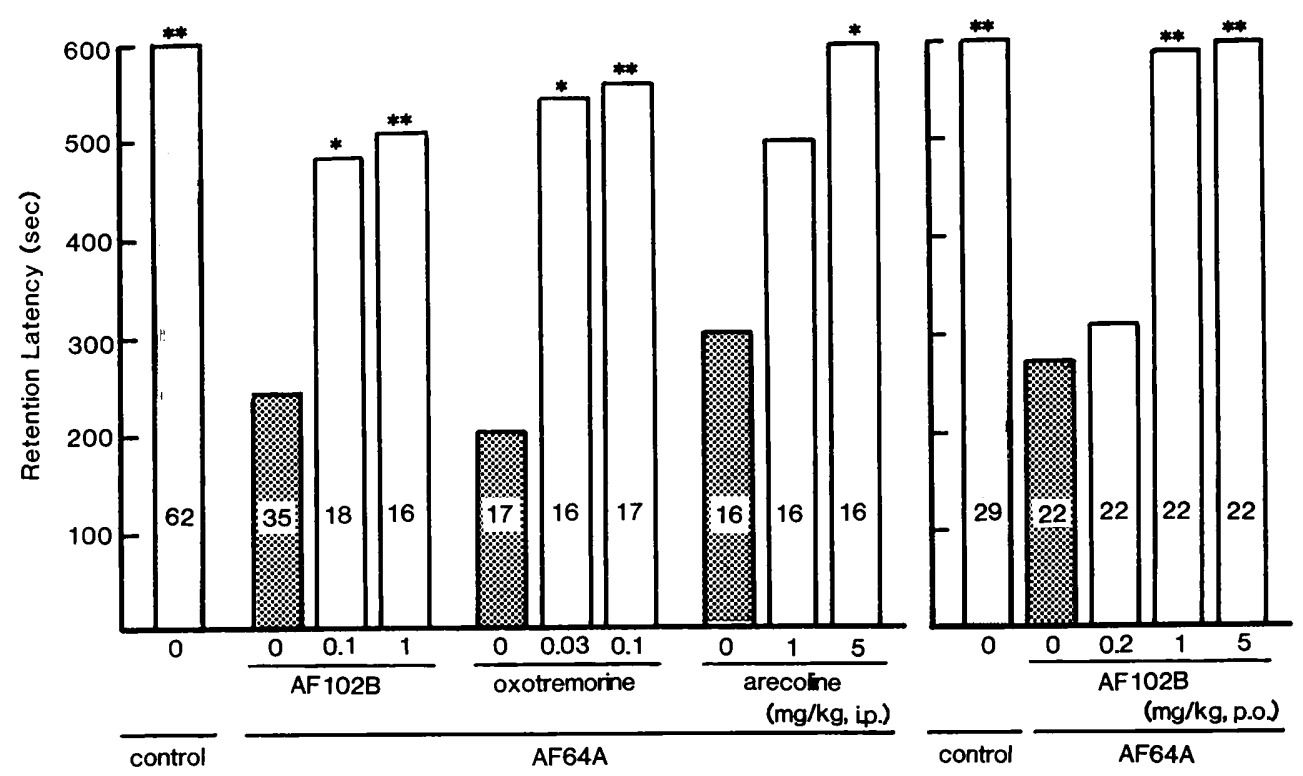

Fig. 1. Effects of AF102B, oxotremorine and arecoline on retention latencies in AF64A-treated rats. Compounds were administered intraperitoneally (a) or perorally (b). Values represent the median with the number of animals in columns. Significantly different from A.F64A-rats receiving vehicle: ${ }^{*} P<0.05$, ${ }^{*} \mathrm{P}<0.01$ (Mann-Whitney $U$-test). 
AF64A-rats at 0.03 and $0.1 \mathrm{mg} / \mathrm{kg}$, i.p. Arecoline also significantly reversed the retention deficits of AF64A-rats at $5 \mathrm{mg} / \mathrm{kg}$, i.p., but not at $1 \mathrm{mg} / \mathrm{kg}$, i.p. With respect to the initial latency in the acquisition trial, there was no significant difference among the three groups in each drug treatment.

When AF102B was perorally administered to AF64A-rats, it produced a dose-dependent amelioration of passive avoidance learning and memory deficits (Fig. 1b). AF102B significantly improved the avoidance performance of AF64A-rats at 1 and $5 \mathrm{mg} / \mathrm{kg}$, p.o. When AF102B was administered at $0.2 \mathrm{mg} /$ $\mathrm{kg}$, p.o., slight but not significant improvement was found. In the acquisition trial, there was no significant difference in the latency time among the five groups, showing that preadministration of AF102B had no influence on the acquisition trial.

The retention latency of SCP-mice receiving distilled water (vehicle) was significantly shorter than of saline-treated control mice. AF102B (1, 5 or $10 \mathrm{mg} / \mathrm{kg}$, i.p.) significantly enhance the retention test performance of SCP-mice (Fig. 2).

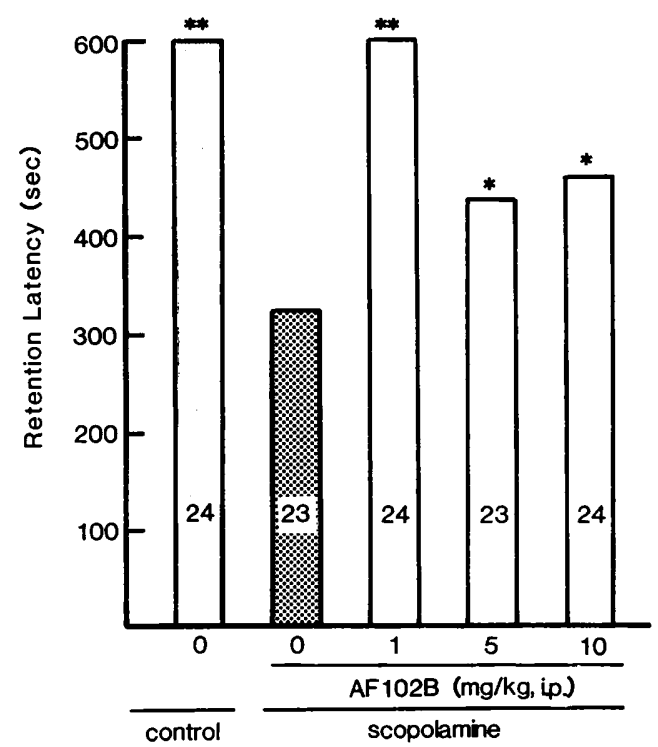

Fig. 2. Effects of AF102B on retention latencies in scopolamine-treated mice. Values represent the median with the number of animals in columns. Significantly different from SCP-mice receiving vehicle: ${ }^{*} P<0.05,{ }^{*} P<0.01$ (Mann-Whitney $U$ test).
AF64A, an irreversible inhibitor of the high affinity uptake of choline, is reported to produce a selective reduction of presynaptic markers in the hippocampal cholinergic system in rats after i.c.v. injection (for review, see ref. 6). Leventer et al. (9) indicate that at low doses ( $\leqq 5 \mathrm{nmol}$ ), the effects of AF64A appear to be limited to the cholinergic system, and that at higher doses, noncholinergic effects become prominent, although selectivity of AF64A towards the cholinergic system is not without controversy. We have recently observed that AF64A injected into the lateral ventricles ( $3 \mathrm{nmol}$, each side) impaired the cognition of rats in a passive avoidance task and in a delayed alternation task in a T-maze with a concomitant hypofunction in the hippocampal cholinergic system (8). Passive avoidance learning and memory deficits are ameliorated by physostigmine $(8,10)$. In the present study, muscarinic agonists improved the defective retention of AF64A-rats in the passive avoidance task. These results suggest that the cognitive impairment produced by AF64A may be due to AF64A-induced changes in hippocampal cholinergic activity rather than being caused by non-specific neural damage.

With respect to the doses of muscarinic agonists for alleviation of AF64A-induced passive avoidance failure, $0.1 \mathrm{mg} / \mathrm{kg}$, i.p. (410 nmol) of $A F 102 B$ and $0.03 \mathrm{mg} / \mathrm{kg}$, i.p. $(79 \mathrm{nmol})$ of oxotremorine had positive effects, but $1 \mathrm{mg} / \mathrm{kg}$, i.p. (4200 nmol) of arecoline had negative effects. This seems partly due to a difference in their affinities to the muscarinic receptor. In our earlier studies on the inhibition of $\left[{ }^{3} \mathrm{H}\right] \mathrm{QNB}$ binding to receptors on rat cerebral cortex membranes and to the purified muscarinic receptor from porcine cerebrum, we found that the apparent $K_{1}$ values in the membrane preparations and the purified receptor are $5.1 \mu \mathrm{M}$ and $10 \mu \mathrm{M}$ for AF102B, $1.3 \mu \mathrm{M}$ and $3.8 \mu \mathrm{M}$ for oxotremorine, and $15 \mu \mathrm{M}$ and $37 \mu \mathrm{M}$ for arecoline, respectively (11). When AF102B was intraperitoneally administered to AF64-rats at $0.1-1 \mathrm{mg} / \mathrm{kg}$ or SCP-mice at $1-5 \mathrm{mg} / \mathrm{kg}$, significant but not dose-dependent improvement was found in the passive avoidance task. It may be suggested that i.p. administration of AF102B is highly potent for amelioration of 
the cognitive impairments caused by AF64A or scopolamine and that the efficacy of each dose has already reached plateaus in these experiments.

Scopolamine, a reversible inhibitor of muscarinic receptors, is known to disrupt cognitive function in humans well as in animals, presumably through central cholinergic dysfunction $(1,4)$. It is reported that a scopolamine-induced cognitive impairment is recovered by physostigmine (4). AF102B also improved the scopolamine-induced amnesia of mice in a passive avoidance task. Taken together, our present results have provided further evidence suggesting that the central cholinegic system has an important role in learning and memory processes $(1,3,4)$. Moreover, AF102B was found to compensate for cholinergic defects caused by AF64A or scopolamine treatment.

SDAT is characterized behaviorally by a general decline in cognitive function. Although several neurotransmitter systems are documented to be impaired (2), one of the most profound neurochemical changes observed is a marked presynaptic cholinergic hypofunction in selective brain regions including the hippocampus $(1,3)$. On the contrary, postsynaptic muscarinic receptors appear to be relatively unaffected $(1,5)$. Mash et al. (12) reported that cerebral cortex samples from SDAT patients exhibit reductions in the number of $M_{2}$ muscarinic receptors located presynaptically with no change in the number of $M_{1}$ receptors located postsynaptically. Pirenzepine, a selective $M_{1}$ antagonist, has been found to be very potent in impairing performance in a passive avoidance task, a Morris water maze and a T-maze in rodents, implying an important role of $M_{1}$ receptors in learning and memory processes (13-15). These findings suggest that selective $M_{1}$ agonists would be potentially useful therapeutic drugs for $\operatorname{SDAT}(3,5)$.

That AF102B may be highly selective for $M_{1}$ receptors is suggested by the results of (a) displacement assays of $\left[{ }^{3} \mathrm{H}\right] \mathrm{ONB}$ binding in the rat forebrain and cerebellum (16). (b) electrophysiological studies on rabbit superior cervical ganglia (17), and (c) neurochemical studies on presynaptic muscarinic autoreceptor and heteroreceptor regulating neurotransmit- ter release (18). In the behavioral studies, we have already observed that AF102B significantly improves the performance of AF64Arats in a T-maze and radial-arm maze tasks (7, 19). Taken together with the present results that AF102B ameliorates experimental amnesia (passive avoidance failure) in AF64A-rats and SCP-mice, AF102B deserves further examination for development as a possible therapeutic drug for SDAT.

\section{References}

1 Bartus, R.T., Dean, R.L., Beer, B. and Lippa, A.S.: The cholinergic hypothesis of geriatric memory dysfunction. Science 217, 408-417 (1982)

2 Rossor, M. and Iversen, L.L.: Non-cholinergic neurotransmitter abnormalities in Alzheimer's disease. Br. Med. Bull. 42, 70-74 (1986)

3 Mizobe, F.: Acetylcholine hypothesis in senile dementia of the Alzheimer type. Biomedica 2, 688-692 (1987) (in Japanese)

4 Collerton, D.: Cholinergic function and intellertual decline in Alzheimer's disease. Neurcscience 19, 1-28 (1986)

5 Hollander, E., Mohs, R.C. and Davis, K.L.: Cholinergic approaches to the treatment of Alzheimer's disease. Br. Med. Bull. 42, 97-100 (1986)

6 Hanin, I., Fisher, A., Hortnagl, H., Levernter, S.M., Potter, P.E. and Walsh, T.J.: Ethylcholine aziridinium (AF64A: ECMA) and other potential cholinergic neuron-specific neurotoxins. In Psychopharmacology: a Third Generation of Progress, Edited by Meltzer, H.Y., p. 341-349, Raven Press, New York (1987)

7 Nakahara, N., Iga, Y., Samuraizono, S., Sawai, T., Katayama, S. and Mizobe, F.: Single and repeated administrations of AF102B, a novel muscarinic agonist, improve cognitive dysfunctions in AF64A-treated rats. Soc. Neurosci. Abstr. 13, 837 (1987)

8 Nakahara, N., Iga, Y., Mizobe, F. and Kawanishi, G.: Effects of intracerebroventricular injection of AF64A on learning behaviors in rats. Japan. J. Pharmacol. 48, 121-130 (1988)

9 Leventer, S.M. and Hanin, I.: AF64A cholinotoxity: Functional aspects. In Senile Dementia of the Alzheimer Type, Edited by Traber, J. and Gispen, W.H., p. 316-324, Springer-Verlag, Berlin (1985)

10 Ogura, H., Yamanishi, Y. and Yamatsu, K.: Effects of physostigmine on AF64A-induced impairment of learning acquisition in rats. Japan. J. Pharmacol. 44, 498-501 (1987) 
11 Mizobe, F., Ono, S., Ohgane, N., Iwamoto, K., Katayama, S. and 'Haga, T.: AF102B, a novel muscarinic M1-type agonist, stimulated presynaptic auto- and heteroreceptors in different potency. Trends Pharmacol. Sci. 9, Supp. 81 (1988)

12 Mash, D.C., Flynn, D.D. and Potter, L.T.: Loss of M2 muscarinic receptors in the cerebral cortex in Alzheimer's disease and experimental cholinergic denervation. Science 228, 1115-1117 (1985)

13 Caulfield, M.P., Higgins, G.A. and Straughan, D.W.: Central administration of the muscarinic receptor subtype-selective antagonist pirenzepine selectively impairs passive avoidance learning in the mouse. J. Pharm. Pharmacol. 35, 131-132 (1983)

14 Hagan, J.J., Jansen, J.H.M. and Broekkamp, C.L.E.: Blockade of spatial learning by the $M_{1}$ muscarinic antagonist pirenzepine. Psychopharmacology (Berlin) 93, 470-476 (1987)

15 Messer, W.S., Jr., Thomas, G.J. and Hoss, W.: Selectivity of pirenzepine in the central nervous system. II. Differential effects of pirenzepine and scopolamine on performance of a representational memory task. Brain Res. 407, 37-45 (1987)

16 Fisher, A., Heldman, E., Brandies, R., Pittel, Z., Dachir, S., Levy, A. and Karton, I.: AF102B: A novel putative $M 1$ agonist reverses AF64Ainduced cognitive impairments in rats. Soc. Neurosci. Abstr. 12, 702 (1986)

17 Mochida, S., Mizobe, F., Fisher, A., Kawanishi, G. and Kobayashi, H.: Dual synaptic effects of activating M1-muscarinic receptors, in superior cervical ganglia of rabbits. Brain Res. 455, 9-17 (1988)

18 Ono, S., Saito, Y., Ohgane, N., Kawanishi, G. and Mizobe, F.: Heterogeneity of muscarinic autoreceptors and heteroreceptors in the rat brain: effects of a novel $M_{1}$ agonist, AF102B. Eur. J. Pharmacol. (1988) (in press)

19 Iga, Y., Nakahara, N., Mizobe, F., Ohgane, N., Sawai, T., Nakajima, I. and Kawanishi, G.: SND5008 (AF102B), novel muscarinic agonist, improves experimental cognitive dysfunction in rodents. Soc. Neursci. Abstr. 14, 57 (1988) 